\title{
Exploring Employment Opportunities through Microtasks via Cybercafes
}

CONFERENCE PAPER $\cdot$ JUNE 2012

DOI: $10.1109 /$ GHTC.2012.21

CITATIONS

2

4 AUTHORS, INCLUDING:

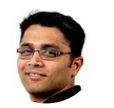

Mrunal Gawade

Centrum Wiskunde \& Informatica

7 PUBLICATIONS 24 CITATIONS

SEE PROFILE
READS

41
Rajan Vaish

Stanford University

13 PUBLICATIONS 30 CITATIONS

SEE PROFILE 


\title{
Exploring employment opportunities through microtasks via cybercafes
}

\author{
Mrunal Gawade ${ }^{1}$, Rajan Vaish ${ }^{2}$, Mercy Nduta Waihumbu, James Davis ${ }^{2}$ \\ ${ }^{1}$ Department of Computer Science \\ Centrum Wiskunde \& Informatica \\ Amsterdam, Netherlands \\ gawade@cwi.nl \\ ${ }^{2}$ Department of Computer Science \\ University of California \\ Santa Cruz, CA, USA \\ rvaish@ucsc.edu,davis@cs.ucsc.edu
}

\begin{abstract}
Microwork in cybercafés is a promising tool for poverty alleviation. For those who cannot afford a computer, cybercafés can serve as a simple payment channel and as a platform to work. However, there are questions about whether workers are interested in working in cybercafés, whether cybercafé owners are willing to host such a set up, and whether workers are skilled enough to earn an acceptable pay rate? We designed experiments in internet/cyber cafes in India and Kenya to investigate these issues. We also investigated whether computers make workers more productive than mobile platforms? In surveys, we found that $99 \%$ of the users wanted to continue with the experiment in cybercafé, while 8 of 9 cybercafé owners showed interest to host this experiment. User typing speed was adequate to earn a pay rate comparable to their existing wages, and the fastest workers were approximately twice as productive using a computer platform.
\end{abstract}

Keywords- Human Computation, Crowdsourcing, Microwork, Cybercafés, Amazon Mechanical Turk (MTurk), ICT4D, India, Kenya.

\section{INTRODUCTION}

Unemployment and underemployment are one of the most pressing problems in society. Over the last half century, the global literacy rate has risen faster than the employment rate. This implies the availability of huge human resources, if they can be reached efficiently.

Business Process Outsourcing (BPO) has a global reach and provides employment, but rarely reaches the poorest populations, or those in remote villages. There have been explicit attempts to extend its reach into rural areas [1]; however these initiatives are capital intensive, and lack the current extent of cyber cafes worldwide.

Crowdsourcing is an industry which might eventually provide income in even the most remote locations [2]. It is in its early stage, and is evolving quickly [3] [4]. The market demand for crowd-sourced work quintupled in 2010 \& almost quadrupled in 2011[5]. One of the first platforms to implement the concept of paid crowdsourcing was Amazon Mechanical Turk (MTurk). MTurk is a workplace for offering low skilled computerized jobs [6] [7]. MTurk offers jobs which pay from \$0.01 up to tens of dollars depending on the complexity of job. Examples include work such as data entry, audio and video transcription, and image labeling. Many of these microtasks are of the sort that humans do easily, but are challenging for computer algorithms [8] [9].

However, the use of this income channel has not been very widespread among the poor. A study by Khanna et al. concluded that lack of a suitable user interface was a barrier [10]. When the interface was improved, work could be completed, but still did not result in an acceptable pay rate for all workers. It is possible that despite its attractiveness, this is not a feasible channel for development.

Our work investigates additional questions related to determining why cybercafés have not yet become informal work centers. Are workers interested in working in cybercafés? Are cybercafé owners willing to host this model? Perhaps the cafes are inconveniently located, the owners aren't willing, or this style of work is simply not interesting. Are the workers skilled enough to earn an acceptable pay rate? Perhaps they lack computer skills, cybercafé rental is too high a cost, or payments are simply too low?

To find answers to these questions, we developed a test application and deployed it in cybercafés in India and Kenya. Workers were paid directly by cybercafé operators, using our funds. Payment was for words typed correctly, since transcription is a common task. In addition to surveys and records kept by café owners, the application logged user activity so that we could measure statistics of interest such as repeat visits and typing speed. We found that café owners and potential workers were overwhelmingly positive about the idea, and typing logs suggest skills at a level necessary for adequate pay.

Some organizations and researchers have targeted work to mobile devices, reasoning that potential workers already have access to this technology platform, and thus don't need to obtain access to a computer at all [11]. This raises one additional question. What is the relative productivity of workers on mobile devices versus computers?

To answer this question we performed a user study with a low income population in Kenya to explicitly compare typing speed on mobile devices and computers. We found that the most skilled users were substantially more productive using computers.

The primary contributions of this paper are the results from our studies, suggesting that workers and owners are interested, 
that low income workers can be skilled enough to earn acceptable wages, and that computers provide a more efficient platform for work, even among the poor.

\section{RELATED WORK}

The primary existing labor channel for development oriented digital work is through employee-employer relationships similar to traditional BPO operations. For example, Samasource [12] assigns microwork to people at the bottom of the pyramid through partnerships with NGOs, where NGOs train the workers and provide the necessary resources to work. Similarly, CloudFactory trains its own workforce, and village BPO operators explicitly follow that model [1]. This paper explores whether the poor can potentially be reached using cybercafés as informally organized work centers.

Many organizations have attempted to deliver microwork through mobile devices, since the penetration of mobile far exceeds that of computers. Examples include MobileWorks, mClerk, and txtEagle [11] [13] [6]. This paper compares the relative efficiency of mobile and computer based data entry.

Attempts to understand the impact and dynamics of cybercafés as work centers have been studied [14]. In 2003, Mutula studied the origin, challenges and growth of the cybercafé industry in Africa [15]. Cybercafés were used to train low-income minority seniors in Los Angeles to cross the digital divide [16]. Overnight use of community centers for employment was investigated in Nigeria [17]. This paper investigates the use of cybercafés specifically as potential centers for informal microwork.

Research comparing input technologies and relative typing speed between devices is common [18] [19] [20]. In the context of development, voice versus typed input has been studied for gathering information from low literacy users [21] [22] [23] [24]. This paper compares typing speed on mobile devices and computers in a low-skill population.

\section{THE EXPERIMENTAL SETUP}

Experiments in cybercafés in India and Kenya were conducted on an application specifically designed to test the typing speed, and thus earning potential, of workers. Figure 1 is a screen shot of the application where users type the falling words. Money earned for correctly typed words is displayed. Words can be typed in any order and are no longer available when they reached the bottom of the screen.

The application was developed in Adobe Flash 10, and saved user logs locally in XML since the workers performed their work unsupervised. An example log file is shown in figure 2. The dictionary of words was in English.

In India, the payment rate was set at $\$ 0.0011 /$ word or $\$ 0.01$ per 9 words. The words were generated every 1.5 seconds, totaling 40 words per minute. At this rate a perfect user would earn a maximum of \$2.64 an hour. In Kenya we experimented with a lower skill population and changed payment rate to $\$ 0.01$ per 3 words. Monetary values were always discussed in local currency, but are reported here in US Dollars. We use an exchange rate of $50 \mathrm{INR}$ to $1 \mathrm{USD}$, and $100 \mathrm{KSH}$ to $1 \mathrm{USD}$ throughout.

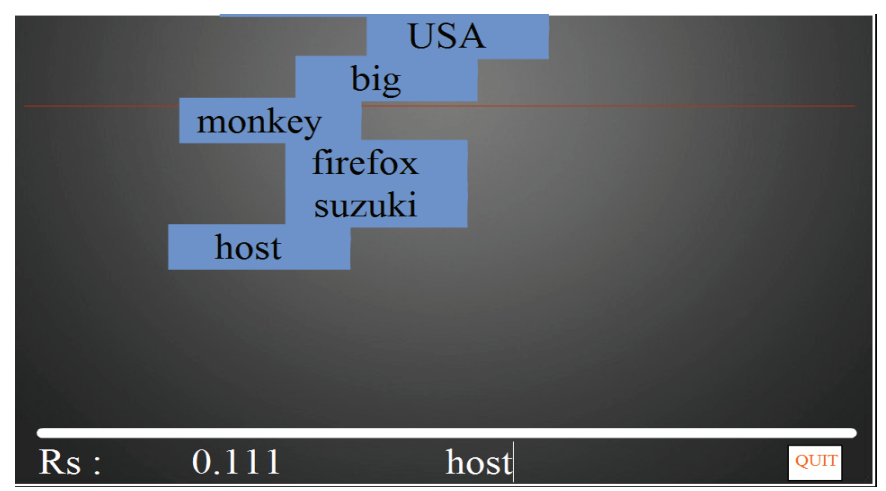

Figure 1. A screen shot of the application developed to test typing skills of low income users in cybercafés.

We also collected surveys from workers and owners, and had cybercafé staff report all earnings in a log book. Money was provided to café owners and distributed to workers at the time work was completed. The paper and digital logs were cross checked, and we did not observe any unexplained discrepancies.

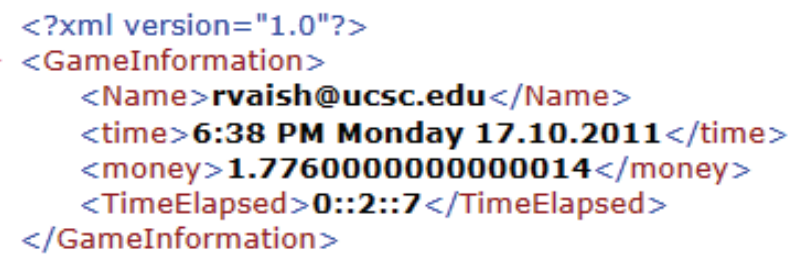

Figure 2. Sample data collected from an auto generated log file.

\section{EXPERIMENTS IN INDIA AND KENYA}

\section{A. India}

We deployed our application in three cybercafés of Pune, Maharashtra, over a period of six months. The locations of the cybercafés were chosen after informally surveying locality, size of cybercafés, number of users visiting cybercafés, hourly fees, and owner interest.

Locality was one of the primary factors in decision making. The first net cafe was chosen in a relatively affluent and residential locality of Aundh in Pune, pictured in figure 3. The second cybercafé was chosen in the midst of one of the busiest roads surrounded by a number of educational institutes on the J.M. Road in Pune. The third net cafe was chosen next to the University of Pune, with a mix of college going and job seeker crowd. The users were trained via a "walkthrough power point presentation" and/or cybercafé owners. After that, the users were welcome to work as long and often as they wished, subject to a maximum daily earning of $\$ 2$.

Table I shows the demographic data for users in India. The income and education levels were higher than we intended, including primarily college students. In order to validate that our findings generalize, we repeated the experiment in a lower income settlement in a second country (Kibera, Kenya).

We also conducted a second survey of café owners in Bhubaneshwar, Orissa, aimed at judging both the interest of owners and their financial ability to participate. 


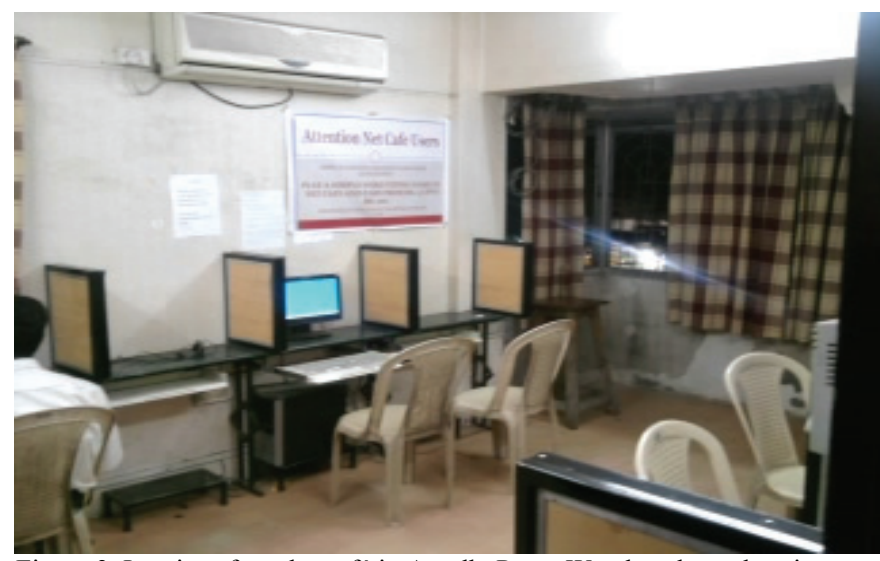

Figure 3. Interior of a cybercafé in Aundh, Pune. We placed an advertisemen poster to attract cybercafé customers to our experimental employment opportunity.

TABLE I. DEMOGRAPHICS OF SUBJECTS INDIA AND KENYA

\begin{tabular}{|l|r|r|}
\hline \multicolumn{3}{|c|}{ Demographics } \\
\hline & India & Kenya \\
\hline Occuptation & 67 & 2 \\
\hline Students & 38 & 17 \\
\hline Working professionals & 0 & 4 \\
\hline Unknown & & \\
\hline Education & 7 & 4 \\
\hline Below high school & 29 & 13 \\
\hline High school & 69 & 3 \\
\hline Abouve High school & 0 & 3 \\
\hline Unknown & & \\
\hline Monthly income & 0 & 6 \\
\hline Below 100 USD & 16 & 7 \\
\hline 100 USD - 200 USD & 6 & 2 \\
\hline 200 USD - 400 USD & 25 & 0 \\
\hline 400 USD - 600 USD & 33 & 0 \\
\hline Above 600 USD & 25 & 8 \\
\hline Unknown & & \\
\hline
\end{tabular}

\section{B. Kenya}

The experiments in Kenya were conducted during a period of 15 days. The application was deployed in two cybercafés in Kibera, a slum in Nairobi. The café owners handled payment, just as in Pune, but were not asked to keep records of users or payments. Figure 4 shows the external view while figure 5 shows the interior of one of the cybercafes, with a worker using our application.

In addition to the test application, a user study was performed to compare typing speed on basic mobile devices, mobiles with mini-keyboards, and computers. Twenty three users were given 3 minutes on each device to transcribe as many words as possible from a sheet of paper. These users were also surveyed for income, education, and computer knowledge.

Table I shows the demographics of our user study population in Kenya. While most people had a high-school education, far fewer had college education, and income was substantially lower. Informally, we observed that the youth who hang out at cybercafes had good english language skills and moderate computer skills. We drew participants for the user study from both the cybercafés, and the wider community. We obseved that the older population in Kibera frequently did not speak english, and had frequently never used a computer. All participants were clearly very familiar with their own basic mobile phone.

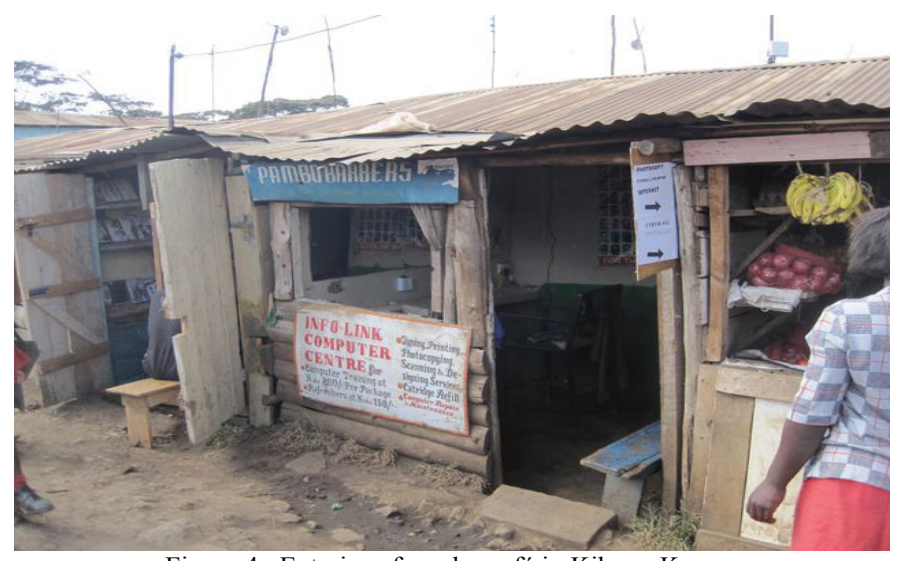

Figure 4. Exterior of a cybercafé in Kibera, Kenya.

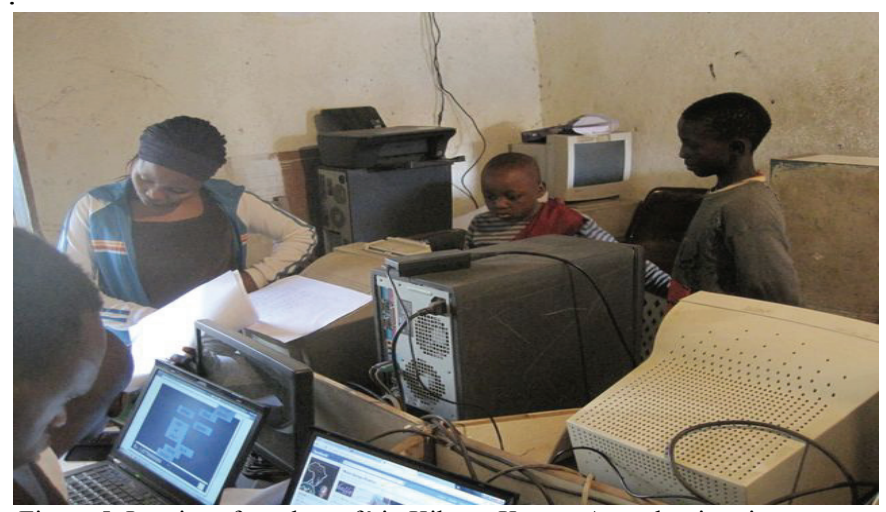

Figure 5. Interior of a cybercafé in Kibera, Kenya. A worker is using our test application on a laptop owned by the cybercafé.

\section{RESULTS}

\section{A. Are workers interested in working in cybercafés?}

Of 105 potential workers surveyed in Pune and 30 in Nairobi, $99 \%$ stated that they would like to do microwork in cybercafés. The survey result is backed up by informal anecdotal observation. In Kibera, competition was observed for the one machine which had the software installed. In addition, the café owners reported reserving a portion of the work for themselves, indicating they thought a meaningful income was available. Lastly, after terminating the experiment some café owners and workers in both locations asked repeatedly to continue the program.

In order to control for participant response bias [25], we also tracked the actual behavior of users when no experimenters were present. Figure 6 shows the frequency of returning users in the residential area of Aundh, Pune. In this location, the experiment spanned the time frame from June to August, long enough for novelty effects to diminish. Blue dots represent returning users, while red dots represent users who 
tried the application only once. Approximately $50 \%$ of the participants returned to use the application, with the maximum being 11 times. Workers sometimes spent up to 4 hours working, with up to 1 hour being quite common.

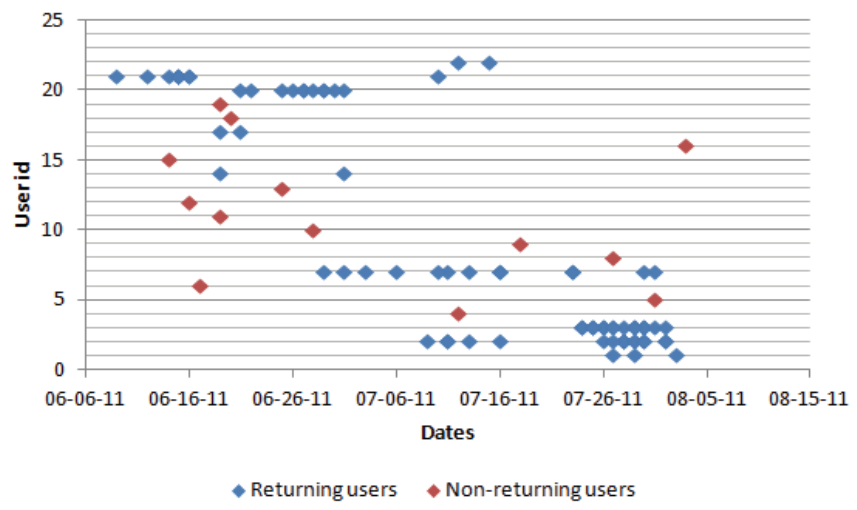

Figure 6. Frequency of returning users at a cybercafé in a residential area of Pune, over a two month period. Blue dots are workers who returned for employment multiple times, while red dots are workers who tried our test application only once. Notice that many workers did return.

We observed very few return users at the Pune cafes located in city center and near the university, although one of those cafes attracted the most total participants (60 users). The Nairobi experiment was too short to measure returning users. We hypothesize that a residential location allowed the café to attracted regular customers who could conveniently return to earn extra money.

Based on the combined evidence of surveys, informal discussions, and the fact that some workers returned multiple times and worked long hours, the authors believe that at least some potential workers actually do consider this a desirable income source.

\section{B. Are Cybercafé owners willing to participate in this initiative?}

The three upscale café owners in Pune were directly compensated, to incentivize them to participate. The two café owners in Kibera enthusiastically participated with no extra compensation. To explore whether other cybercafés would be interested, we surveyed 9 owners in Bhubaneshwar, Orissa. Orissa is one of the least developed states of India. We gathered data on interest, as well as café income, capital costs, and customer base. Some of this data is presented in Table II. We found that 8 of 9 cybercafé owners showed interest in implementing this model. The cafes had a suitably sized customer base, ranging from 20 to 300 , mostly in the 15-30 year old age range. All the owners had a diploma or a graduate degree, which suggests capacity to train workers and manage payment if needed. The internet tariff ranged from $\$ 0.20$ to $\$ 0.40$ per hour, while the bandwidth ranged from $512 \mathrm{Kbps}$ to $5 \mathrm{Mbps}$.

We also asked whether owners would be willing to consider night operations or expanding their café with additional capital outlay. The responses to these questions were less enthusiastic, with slightly less than half agreeing that they could consider those options.

TABLE II. SURVEY RESULTS FROM THE CYBERCAFES OF BHUBANESHWAR, INDIA

\begin{tabular}{|l|l|l|l|l|l|l|}
\hline Cybercafés & Interested & Night Shift & Expansion & $\begin{array}{l}\text { Customers } \\
\text { per day }\end{array}$ & $\begin{array}{l}\text { Monthly } \\
\text { Income }\end{array}$ & $\begin{array}{l}\text { Cybercafe's } \\
\text { Setup cost }\end{array}$ \\
\hline Cybercafé 1 1 & Yes & Yes & Yes & $20-25$ & $\$ 300.00$ & $\$ 1600.00$ \\
\hline Cybercafé 2 & Yes & No & No & $50-55$ & $\$ 500.00$ & $\$ 4000.00$ \\
\hline Cybercafé 3 & Yes & Yes & No & $20-25$ & $\$ 400.00$ & $\$ 8000.00$ \\
\hline Cybercafé 4 4 & Yes & Yes & No & $100-150$ & $\$ 400.00$ & $\$ 8000.00$ \\
\hline Cybercafé 5 & Yes & Yes & Yes & $200-300$ & $\$ 1000.00$ & $\$ 10000.00$ \\
\hline Cybercafé 6 6 & Yes & No & No & $90-100$ & $\$ 700.00$ & $\$ 8000.00$ \\
\hline Cybercafé 7 & Yes & Yes & No & $50-60$ & $\$ 400.00$ & $\$ 4000.00$ \\
\hline Cybercafé 8 & No & No & Yes & $30-35$ & $\$ 400.00$ & $\$ 1800.00$ \\
\hline Cybercafe 9 & Yes & N/A & No & $25-30$ & $\$ 300.00$ & $\$ 800.00$ \\
\hline
\end{tabular}

In order to at least informally check for participant response bias among owners, we also surveyed business owners in an unrelated sector. We asked six owners of water retail points in Kibera to consider our innovative business models such as delivering water to customers, or purifying it prior to sell. All of these owners declined these changes, always providing a reason why it did not make business sense.

Given the combined evidence that some owners participated in our microwork experiment for months, that additional surveyed owners we positive, and that owners in other business sectors were willing to state non-interest, the authors believe that at least some cybercafés would be interested to serve as work and payment distribution points.

\section{Are the workers skilled enough to earn an acceptable pay rate?}

To determine the efficiency of workers, we analyzed the data collected by our test application. Figure 7 plots the actual time spent and money earned by our participants. There were both fast and slow workers. Some stopped after only a few minutes and some worked for over an hour. A few continued until the reached our maximum daily income of $\$ 2$. Notice that most workers earned in the $\$ 0.50-\$ 1.75$ per hour range.

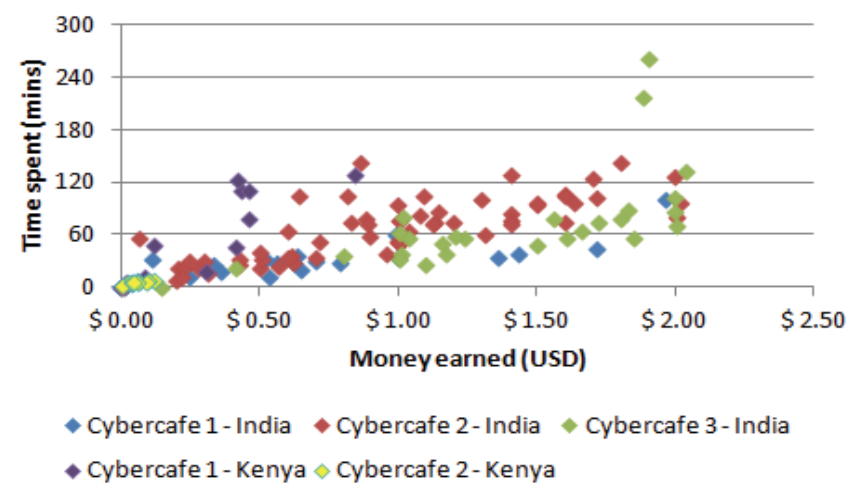

Figure 7. Analysis of time spent and money earned by actual users. Most workers earned between $\$ 0.50-\$ 1.75$ per hour. Notice that some workers sat and used our application for more than 2 hours, even when earning relatively little. 
The measured actual earnings are dependent on our arbitrarily set pay rate of $\$ 0.0011 /$ word in India and $\$ 0.0033 /$ word in Kenya. We used these rates because the going rate in summer 2011 for transcribing 1000 CAPTCHAs was between $\$ 1$ to $\$ 10$. Our pay rate in India was near the low end of this range, while in Kenya we paid near the median. Gupta et al. reported commercial transcription costs in India in the \$0.004-\$0.01/word range, so we believe we paid appropriately [13].

Since typing speed is directly correlated with earnings and independent of our arbitrary payment choices, we plot this directly in figure 8 . This report is for total words over total time, including distracted workers who used another application while leaving our test application open in the background. Thus burst typing speed was higher than reported here. The relatively more educated workers in India averaged 18.9 words per minute, while those in Kibera averaged 7.4 words per minute. In both cases there was a range of typing speeds.

Assuming the measured typing speeds and a pay rate of $\$ 0.002 /$ word, at $8 \mathrm{hrs} /$ day we obtain pay rates in the $\$ 6-10 /$ day range in Kibera, and \$10-20/day in Pune. Equivalently, about \$150-\$300/month in Kibera, and \$200-\$600/month in Pune. This pay rate is comparable to the existing reported incomes of our workers. The fastest workers earned more than this, and we believe that with daily practice all the workers would improve their skills, and thus their earnings.

The authors believe that despite relatively slow typing speeds, especially in Kibera, computer skills are good enough that digital microwork provides a plausible income source.

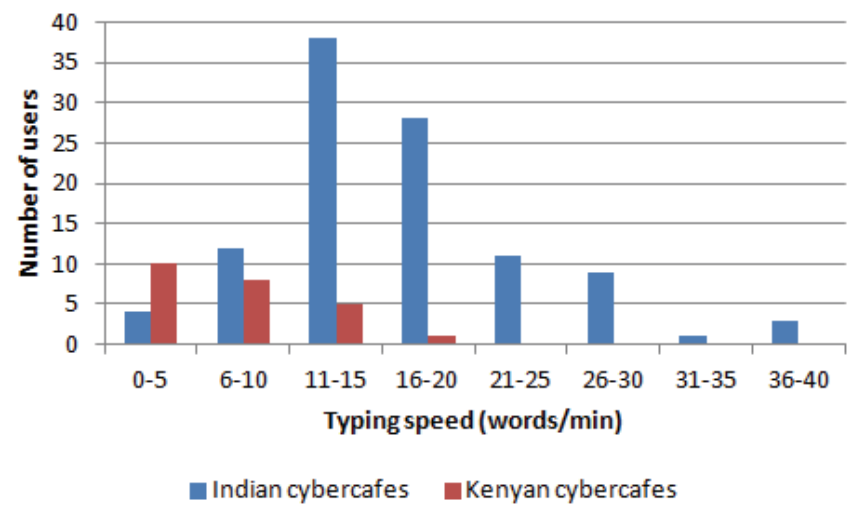

Figure 8. Typing speed of workers using our test application in cybercafés. The relatively more educated workers in Pune typed faster than the workers in Kibera. Notice that there is a large variation in typing skill in both locations.

D. What is the relative productivity of workers on mobile devices versus computers?

Since many organizations are targeting microwork to mobile devices, we conducted a separate user study in Kibera measuring typing speed. Twenty three users were asked to transcribe as much as possible in 3 minutes from a sheet of paper, using each of: a basic mobile phone, a Nokia N900 with mini-QWERTY keyboard, and a netbook computer, shown in figure 9.
Results are plotted in figure 10, sorted by speed of participant. The user IDs are sorted independently per device. Some users were faster on basic mobile than computer. However, on average, the least technologically literate half of the users were approximately the same speed on mobile and computer. In contrast the fastest user was almost twice as fast on a computer. The average typing speed for N95, N900 and Net book was $6.8,7.3$ and 9.4 words per minute respectively.

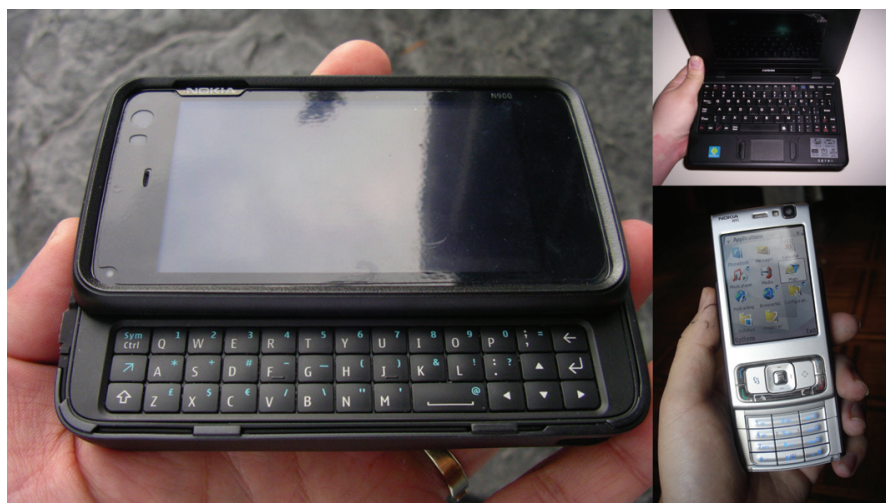

Figure 9. Nokia N900, Netbook, and Nokia N95 that were used for a user study of typing speed on different platforms.

We brought a Nokia N95 with us, but most users owned and all knew how to use a basic mobile already. We tested basic mobile text entry on the users own phone when possible. Some users had to be taught how to use the mini-QWERTY and computer keyboards. Thus we expect that practice would increase these speeds more than the basic mobile speed.

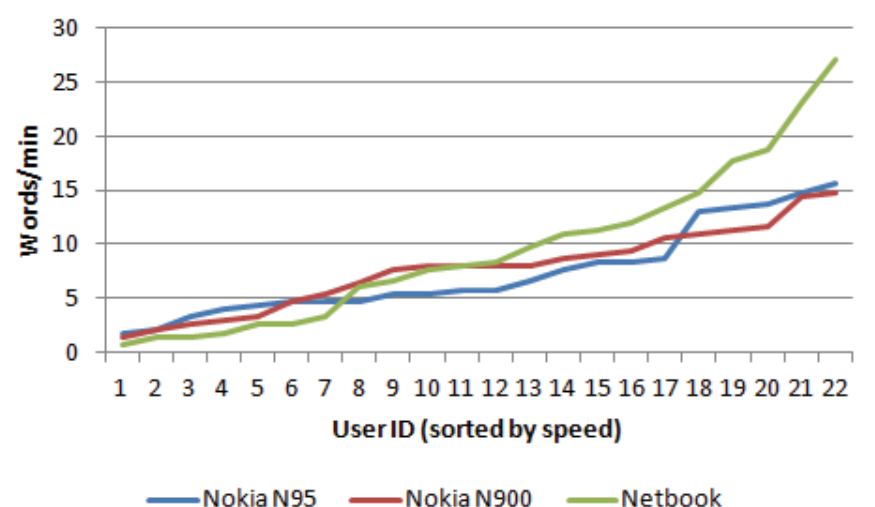

Figure 10. Comparative analysis of transcription speed in a 3-minute test, using basic mobile input (N95), mini-keyboard (N900) and netbook. The slower half of the users were approximately the same speed on all devices, while the fastest users were noticeably faster on a computer.

The additional average 2.6 words/minute possible on a computer translates to about $\$ 2.50$ per work day, assuming $\$ 0.002$ /word. Assuming that cybercafé owners kept $50 \%$ of this extra income and were open two shifts a day, the capital cost of a low end $\$ 300$ computer would be repaid in 4 months.

Based on the measured typing speeds, the capital cost of computers and the expectation that practice would improve the interface advantage of computers further, the authors conclude 
that cybercafés offer a cost effective alternative to mobile data entry for populations that cannot afford personal computers.

\section{CONCLUSIONS}

Digital microwork using cybercafés as informal work centers is a promising income source for the poor. Since this practice is not yet widespread, there must be some factor preventing adoption. This paper has explored several possibilities: worker interest, owner interest, skill levels, and platform alternatives.

We deployed a test application in five cafes in two countries. In addition to usage statistics we surveyed both workers and café owners about attitudes and income demographics.

We conclude that the workers are interested, the café owners are interested, and the workers are skilled enough to earn acceptable wages.

In addition we compare worker efficiency on basic mobile devices and computers, and conclude that computers provide efficiency gains, even among low skill, low income subjects.

\section{REFERENCES}

[1] S. Malhotra, P. Rathi, T. A. Gonsalves, A. Jhunjhunwala, T. Giri, "Untapped Resources! Amazing Potential! TeNeT's Rural BPO Initiative", in IPIP International Federation for Information Processing, Volume 241, Home Informatics and Telematics: ICT for the Next Billion, Springer 2007, pp. 21-33.

[2] W. Thies, A. Ratan. J. Davis. "Paid Crowdsourcing as a Vehicle for Global Development", ACM CHI 2011 Workshop on Crowdsourcing and Human Computation.

[3] B. Frei, "Paid Crowdsourcing: Current State \& Progress towards Mainstream Business Use". Smartsheet White Paper, Sep 2009.

[4] I. Medhi, G. Menon, and K. Toyama, "Challenges of computerized jobsearch in the developing world". CHI, 2008.

[5] BUSINESSGROW, 2011, Retrieved April 2012. http://www.businessesgrow.com/2011/12/13/enterprise-crowdsourcingblasts-off-as-social-media-growth-industry/

[6] N. Eagle, "txteagle: Mobile Crowdsourcing", In Internationalization, Design and Global Development, 2009.

[7] S. Chen, M. Ravallion, "The Developing World Is Poorer Than We Thought, But No Less Successful in the Fight against Poverty", Policy Research Working Paper 4703, The World Bank, Development Research Group, Aug 2008.

[8] J. Ross, L. Irani, M. S. Silberman, A. Zaldivar, and B. Tomlinson, "Who are the Crowdworkers? Shifting Demographics in Amazon Mechanical Turk", In alt.CHI, 2010

[9] J. Zittrain, "Ubiquitous human computing", Philosophical Transactions of the Royal Society, 366, 2008.

[10] S. Khanna, A. Ratan, J. Davis. W. Thies, "Evaluating and Improving the Usability of Mechanical Turk for Low-Income Workers in India", ACM DEV 2010.

[11] P. Narula, P. Gutheim, D. Rolnitzky, A. Kulkarni, B. Hartmann, 2011, "MobileWorks: A Mobile Crowdsourcing Platform for Workers at the Bottom of the Pyramid", 3rd Human Computation Workshop (HCOMP 2011).

[12] SAMASOURCE, 2012, Retrieved April 2012. http://samasource.org/

[13] A. Gupta, W. Thies, E. Cutrell, R. Balakrishnan, "mClerk: Enabling mobile crowdsourcing in developing regions", In Proceedings of CHI 2012, Human Factors in Computing Systems, (Austin), ACM press.

[14] S. Liff, F. Steward, "Shaping e-Access in the Cybercafé: Networks, Boundaries and Heterotopian Innovation", New Media \& Society September 2003 vol. 5 no. 3 313-334.
[15] S. M. Mutula, "Cyber café industry in Africa", Journal of Information Science November 2003 vol. 29 no. 6 489-497

[16] Y. Jung, W. Peng, M. Moran, S. A. Jin, M. McLaughlin, M. Cody, M. J. Marsh, J. Albright, M. Silverstein, "Low-Income Minority Seniors' Enrollment in a Cybercafé: Psychological Barriers to Crossing the Digital Divide", Taylor \& Francis, Educational Gerontology, Volume 36, Issue 3, 2010, pp.193-212.

[17] E.E. Adomi, "Overnight Internet Browsing Among Cyber Café users in Abraka, Nigeria", The Journal of Community Informatics, Vol 3, No 2 (2007).

[18] K. Lyons, T. starner, D. Plaisted, J. Fusia, A. Lyons, A. Drew, E. W. Looney, "Twiddler typing: one-handed chording text entry for mobile phones", In Proceedings of the SIGCHI conference on Human factors in computing systems, CHI 2004.

[19] N. Green, J. Kruger, C. Faldu, R. S. Amant, "A reduced QWERTY keyboard for mobile text entry.", In CHI 2004 extended abstracts on Human factors in computing systems.

[20] E. Matias, S. MacKenzie, W. Buxton, "One-handed touch typing on a QWERTY keyboard." Hum.-Comput. Interact. 11, 1 (March 1996), 127.

[21] N. Patel, S. Agarwal, N. Rajput, A. Nanavati, P. Dave, T. Parikh, “A Comparative Study of Speech and Dialed Input Voice Interfaces in Rural India", In Proceedings of ACM Conference on Human Factors in Computing Systems, CHI 2009.

[22] J. Sherwani, S. Palijo, S. Mirza, T. Ahmed, N. Ali, R. Rosenfeld, "Speech vs. Touch-tone: Telephony Interfaces for Information Access by Low Literate Users." In Proc. Information \& Communications Technologies and Development, Doha, Qatar, April 2009.

[23] S. Patnaik, E. Brunskill, W. Thies, "Evaluating the accuracy of data collection on mobile phones: a study of forms, sms, and voice", In the Proceedings of the 3rd international conference on Information and communication technologies and development, ICTD 2009.

[24] I. Medhi, S. Patnaik, E. Brunskill, S. N. N. Gautama, W. Thies, K. Toyama, "Designing mobile interfaces for novice and low-literacy users", ACM Transactions on Computer-Human Interaction, Volume 18 Issue 1, April 2011.

[25] N. Dell, V. Vaidyanathan, I. Medhi, E. Cutrell, W. Thies, ""Yours is Better!" Participant Response Bias in HCI", the ACM SIGCHI Conference on Human Factors in Computing Systems 2012. 